\title{
La mujer como víctima y actor del conflicto armado en Colombia*
}

\author{
Woman as victim and actor of the armed conflict in Colombia \\ A mulher como vítima e ator do conflito armado na Colômbia*
}

\begin{tabular}{l} 
Oerspectivas \\
\hline \begin{tabular}{c} 
Cúcuta-Colombia \\
\hline Vol. 1
\end{tabular} \\
\hline No. 1 \\
\hline Jul - Dic 2016 \\
\hline $\begin{array}{l}\text { ISSN: } 2590-9215 \\
\text { (En línea) }\end{array}$ \\
PP: $73-80$
\end{tabular}

\author{
Erika Tatiana Ayala**, Eduardo Gabriel Osorio***
}

Forma de citar: Ayala, E. T., y Osorio, E. G. (2016). La mujer como víctima y actor del conflicto armado en Colombia. Perspectivas. 1(1). 73-80.

Recibido:

Febrero 20 de 2016

Aceptado:

Mayo 06 de 2016

\section{Resumen}

El artículo tiene como objetivo visibilizar las consecuencias del conflicto armado interno en la mujer colombiana, reflexionando en torno a los hechos victimizantes a los que ha sido sometido el colectivo femenino y las políticas públicas planteadas o desarrolladas como mecanismo de reparación integral a las víctimas. Para tal fin se utilizó como metodología la revisión documental seguida de la sistematización y selección de la información obtenida para su posterior análisis, a través del cual se obtuvo como resultado relevante la continuidad de los riesgos y la vulneración de los derechos y libertades fundamentales contra las mujeres derivados del conflicto armado colombiano, pese a los adelantos en materia de superación de la impunidad, dejando en evidencia la necesidad de establecer políticas estatales integrales.

Palabras clave: Conflicto armado, derechos humanos, mujer, reparación integral, violencia sexual.

\begin{abstract}
The article seeks to make visible the consequences of the internal armed conflict on the Colombian woman, reflecting on the victimizing facts to which the female group has been subjected and the public policies raised or developed as a mechanism of integral reparation to the victims. For this purpose, the documentary review followed by the systematization and selection of the information obtained for its subsequent analysis was used as a methodology, through which the continuity of risks and the violation of fundamental rights and freedoms against The women derived from the Colombian armed conflict, despite advances in overcoming impunity, highlighting the need to set comprehensive state policies.
\end{abstract}

Keywords : Armed conflict, human rights, women, full redress of victim, sexual violence.

\footnotetext{
"Este artículo se deriva del proyecto de investigación "La reparación simbólica de la mujer víctima del conflicto armado en Colombia a través del arte y la arquitectura" financiado por la Universidad Francisco de Paula Santander.

${ }^{* *}$ Arquitecta. Ph.D (c) en Arquitectura de la Universidad Politécnica de Cataluña. Barcelona-España. M.Sc Estudios Territoriales y de la Población de la Universidad Autónoma de Barcelona. Barcelona-España. M.Sc. Teoría e Historia de la Arquitectura de la Universidad Politécnica de Cataluña Barcelona-España. Directora Departamento Arquitectura Diseño y Urbanismo de la Universidad Francisco de Paula Santander, Directora Grupo de Investigación Taller de Arquitectura y Dinámicas del Territorio TAR_GET /UFPS. Representante de Investigación Facultad de Educación, Artes y Humanidades UFPS. erikatatianaayala@ufps.edu.co

${ }^{*}$ A** Abogado. Ph.D en Derecho público de la Universidad Autónoma de Barcelona, Barcelona-España. LLM Derecho Público de la Universidad Autónoma de Barcelona, Barcelona-España. Especialista en Derecho Administrativo de la Universidad Santo Tomas. Docente adscrito al Programa de Derecho de la Universidad Francisco de Paula Santander, miembro investigador del Grupo Jurídico Comercial y Fronterizo/ UFPS. Fundador del Observatorio de Derecho Público y Derechos Humanos del Norte de Santander. eduardogabrielos@ufps.edu.co
} 
Cúcuta-Colombia

Vol. 1

No. 1

Jul - Dic 2016

ISSN: $2590-9215$

(En línea)

PP: $73-80$

\begin{abstract}
Resumo
O artigo tem como objetivo tornar visível o impacto dos conflitos armados internos na mulher colombiana, refletindo em volta aos fatos acontecidos sobre o coletivo feminino e as políticas públicas apresentadas ou desenvolvidas como um mecanismo de reparação integral às vítimas. Para este efeito, tem se empregado como metodologia a revisão de documentos seguida pela sistematização e selecção de informações obtidas para análise adicional, através do qual obteve - se como resultado a continuidade dos riscos e violação dos direitos e liberdades fundamentais contra as mulheres, como resultado do conflito armado colombiano, apesar dos avanços na superação da impunidade, destacando a necessidade de estabelecer políticas estaduais abrangentes.
\end{abstract}

Palavras chave: direitos humanos, conflitos armados, violência sexual, mulher,compensação total.

\section{Introducción.}

El conflicto armado interno en Colombia se originó hace más de 50 años y se ha caracterizado por la vinculación directa de la sociedad civil, propiciando que su población deba asumir de manera directa e indiscriminada la vulneración de sus derechos fundamentales por medio de delitos graves de lesa humanidad como la desaparición forzada, las masacres y los abusos sexuales, entre otros. Ante este panorama, los organismos internacionales como La UNICEF, la Defensoría del Pueblo (2002) y la Corte Interamericana de Derechos humanos (2006), han acompañado y documentado el proceso del conflicto armado colombiano y se han pronunciado reiteradamente, asegurando que las problemáticas derivadas del mismo afectan significativamente a la población más vulnerable de la sociedad: Los niños, niñas, adolescentes y las mujeres.

Desde esta perspectiva, la ley 1448 de 2011 establece dentro del artículo 13 el enfoque diferencial, planteada como una ley que orienta los procesos, las medidas y las acciones tendientes a asistir, proteger y reparar integralmente a las víctimas (Ministerio del Interior Republica de Colombia, 2012), reconociendo así mismo la existencia de poblaciones que manifiestan características particulares con respecto a la edad, el género, la orientación sexual y la situación de discapacidad. De la misma manera, en el informe denominado "mujeres y conflicto armado" presentado por la USAID, la Organización Internacional para las migraciones y la Unidad para la Atención y Reparación Integral de las víctimas se destaca la importancia de estas medidas como marcos normativos en los que se identifican a las mujeres como sujetos de especial protección, brindando soporte a la solicitud de garantías y medidas de protección para la población vulnerable víctima del conflicto armado colombiano.

Así mismo, la Corte Constitucional dentro del Auto 092 de 2008 reúne las denuncias presentadas por las organizaciones de mujeres en las cuales se mencionan la vulneración sistemática de derechos fundamentales por motivo de masacres, tomas armadas, amedrentamiento, violencia sexual; entre otros delitos perpetrados a jóvenes, niñas niños y mujeres, así como la adopción de medidas para la protección de las mujeres víctimas del desplazamiento forzado por causa del conflicto armado colombiano. Por otro lado, como documento de políticas públicas y bajo un enfoque específico hacia el colectivo de la mujer, el CONPES 3784 del 2013 presenta 
como eje general la garantía, la protección y el objetivo pleno de sus derechos a la atención, asistencia y reparación integral, por medio de diversas estrategias dentro de las cuales se prevé la implementación de medidas de acceso a la justicia con enfoques basados en los derechos humanos, el género, el enfoque diferencial y basado en las orientaciones de la justicia transicional.

De igual manera, la $\mathrm{ABC}$ Colombia y la Corporación Sisma Mujer en el informe "Colombia: mujeres, violencia sexual en el conflicto y el proceso de paz" aseguran que desde una perspectiva de género las ONG de mujeres han desarrollado grandes esfuerzos, entre los que se destacan campañas como "Violaciones y otras violencias: Saquen mi cuerpo de la guerra", estudio realizado entre los años 2001 y 2009, donde se muestra, entre otra información crítica, los 54.410 casos de mujeres afectadas por la violencia sexual en el marco del conflicto armado colombiano (p. 7).

El conflicto armado en Colombia, se ha presentado como el escenario propicio para reunir los crímenes derivados de una barbarie que afecta directamente a su población, generando la necesidad de establecer espacios de discusión que conlleven al estudio detallado de los colectivos sociales más vulnerados dentro del mismo. Desde esta perspectiva, la violencia contra la mujer se ha convertido en uno de los puntos neurálgicos dentro del conflicto, debido a que los testimonios presentados por las víctimas y los estudios derivados de los mismos, han permitido establecer los diferentes tipos de violencia a los que han sido sometidas; resaltando la violencia física, la psicológica y la sexual, bajo aspectos determinantes como la opresión, la intimidación, la atemorización y la subordinación (Ruta Pacifica de las mujeres, 2013, pp. 40-46). De esta manera, el presente artículo tiene como objetivo general visibilizar las consecuencias del conflicto armado interno en la mujer colombiana, reflexionando en torno a los hechos victimizantes a los que ha sido sometido el colectivo femenino y las políticas públicas planteadas o desarrolladas como mecanismo de reparación integral a las victimas, así como los obstáculos que la mujer ha encontrado al momento de disfrutar sus derechos fundamentales.

\section{Recursos, Materiales y métodos}

Los resultados presentados en el siguiente escrito hacen parte del proyecto de investigación denominado "La reparación simbólica de la mujer víctima del conflicto armado en Colombia a través del arte y la arquitectura", financiado por la Universidad Francisco de Paula Santander, bajo el contrato 027-2015 y desarrollado interdisciplinarmente por los grupos de investigación TARGET, GIESPPAZ Y GIJCF, la información ha sido recopilada partir de la documentación publicada en los ámbitos tanto nacionales como internacionales referentes a las problemáticas y consecuencias derivadas del conflicto armado colombiano, haciendo un énfasis especial en el colectivo de la mujer. La metodología se ha desarrollado a partir de una revisión documental, seguida de la sistematización y selección de los recursos obtenidos para su posterior análisis.

La revisión documental se centró en la búsqueda y selección de bibliografía referente a las consecuencias derivadas del marco general del conflicto armado colombiano, el papel de la mujer dentro del mismo, los hechos victimizantes a los que ha sido sometido el colectivo femenino y las políticas públicas planteadas o desarrolladas como mecanismo de reparación integral a las victimas dentro del marco de la justicia transicional. La búsqueda de la información se realizó a través de bases de datos bibliográficas como Scopus, Mendeley, Science Direct y Dialnet, así como en relatorías procedentes de corporaciones judiciales como la Corte Constitucional, el Concejo de Estado y la Corte Suprema de 
Justicia procediendo a la recuperación de material relevante al objeto de estudio para su posterior análisis y discusión.

\section{Resultados.}

En el año 2008 la Corte Constitucional ordena a través del Auto 092 medidas encaminadas a superar la impunidad por medio de las cuales se establecen los temas referentes a las mujeres víctimas de conflicto armado bajo un alto nivel de prioridad para la agenda del gobierno nacional, identificando los riesgos que sufre el colectivo femenino inherentes a su condición de género, dentro de los cuales se destacan:

El riesgo de violencia sexual, explotación sexual o abuso sexual, el riesgo de explotación o esclavización para ejercer labores domésticas y roles considerados femeninos en una sociedad con rasgos patriarcales, por parte de los actores armados ilegales; el riesgo de reclutamiento forzado de sus hijos e hijas por los actores armados al margen de la ley, o de otro tipo de amenazas contra ellos, que se hace más grave cuando la mujer es cabeza de familia; los riesgos derivados del contacto o de las relaciones familiares o personales -voluntarias, accidentales o presuntas- con los integrantes de alguno de los grupos armados ilegales que operan en el país o con miembros de la Fuerza Pública, principalmente por señalamientos o retaliaciones efectuados a posteriori por los bandos ilegales enemigos.

(...) los riesgos derivados de su pertenencia a organizaciones sociales, comunitarias o políticas de mujeres, o de sus labores de liderazgo y promoción de los derechos humanos en zonas afectadas por el conflicto armado; el riesgo de persecución y asesinato por las estrategias de control coercitivo del comportamiento público y privado de las personas que implementan los grupos armados ilegales en extensas áreas del territorio nacional; el riesgo por el asesinato o desaparición de su proveedor económico o por la desintegración de sus grupos familiares y de sus redes de apoyo material y social; el riesgo de ser despojadas de sus tierras y su patrimonio con mayor facilidad por los actores armados ilegales dada su posición histórica ante la propiedad, especialmente las propiedades inmuebles rurales; los riesgos derivados de la condición de discriminación y vulnerabilidad acentuada de las mujeres indígenas y afrodescendientes; y el riesgo por la pérdida o ausencia de su compañero o proveedor económico durante el proceso de desplazamiento (FJ II.1).

Estos riesgos obedecen al desconocimiento del enfoque de género tanto en el desarrollo del conflicto armado interno colombiano como en la posterior investigación judicial de sus consecuencias, lo que ha propiciado la trasgresión de los principios de no discriminación y de igualdad así como la garantía de los derechos humanos de las mujeres y niñas (Grupo de Trabajo Mujer y género, por la verdad, la justicia, la reparacion y la reconciliación, 2008, p. 166).

Sin embargo, en enero de 2015 a través del Auto 009, la misma Corte estudia el cumplimiento de dicho auto y destaca la continuidad de los hechos y riesgos contra las mujeres derivados del conflicto armado colombiano, haciendo un énfasis especial en la violencia sexual y resaltando que esta práctica:

(...) no fue producto del desenfreno casual y aislado de los combatientes de baja jerarquía dentro de las organizaciones armadas; sino que por el contrario, fue producto de los 
incentivos y las sanciones deliberadas de las altas cúpulas o jerarquías de las organizaciones hacia la totalidad de sus combatientes (...) (FJ 1).

De la misma manera, la Corte emitió órdenes direccionadas a la superación de la impunidad de la violencia sexual como respuesta a las falencias de atención, protección y acceso a la justicia de la mujer víctima del conflicto armado. Destacando a su vez que dentro de los casos de violencia sexual realizados por los actores armados se incluyen otras vulneraciones como la tortura física y psicológica, actos de ferocidad y barbarie, abusos, violaciones, secuestros e intromisiones abusivas; entre otros, así como prácticas de planificación reproductiva forzada, embarazos y abortos forzosos y el contagio de enfermedades de transmisión sexual (Corte Constitucional, 2015) (FJ 1).

De esta manera, dentro del Sexto informe de seguimiento al Auto 092 de 2008 y el primer informe de seguimiento al Auto 009 de 2015 desarrollado por la mesa de mujeres asociadas al conflicto armado (2016) compuesta por la Alianza iniciativa de mujeres colombianas por la paz, la liga de mujeres desplazadas, la Corporación casa de la mujer, la Corporación Sisma mujer, la mesa de trabajo mujer y conflicto armado, el Observatorio de género, democracia y derechos humanos, la Ruta Pacifica de las Mujeres y el Centro de Estudios de Derecho, Justicia y Sociedad; entre otros actores, se establece que aunque las entidades competentes han realizado avances en materia de la superación de la impunidad, los mismos no son efectivos ni suficientes para garantizar los derechos a la verdad, la justicia y la reparación de las víctimas, estableciendo como falencia principal la falta de articulación intra e interinstitucional para abordar las temáticas establecidas por la Corte Constitucional con respecto a la adopción de una política estatal integral, tal como se había establecido en el Auto 092.
La anterior situación de vulnerabilidad, se hace palpable si se observa el Registro Único de Victimas en Colombia, el cual evidencia que se han reconocido como victimas un total de 7.762.840 personas, de las cuales 3.853.106 corresponden al colectivo femenino (Unidad para la atención y reparación integral a las victimas, 2016), dejando en evidencia que en el país aproximadamente el $50 \%$ de las víctimas del conflicto armado interno corresponden a este género. Así mismo, la Comisión Interamericana de Derechos Humanos (1999) ha manifestado reiteradamente su preocupación en torno a la grave situación de violencia y violación sistemática de derechos humanos presente en el territorio colombiano, resaltando que dentro del conflicto armado de cada 100 mujeres 43 han sido vulneradas, factor que actúa en contravía a lo establecido por la jurisprudencia internacional donde se establece que es un deber del Estado actuar con diligencia para proteger los derechos humanos y el derecho que poseen las mujeres de vivir libres de discriminación y violencia.

\section{Discusión.}

Dentro de las problemáticas derivadas del conflicto armado en relación a colectivo femenino, alguno autores como Cadavid Rico (2014) aseguran que la violencia de género tiene sus raíces en la estructura socio económica y política de corte patriarcal característica de las sociedades en conflicto, evidenciando de esta manera prácticas que giran en torno a estereotipos donde la fuerza, el poder y el dominio masculino prevalecen sobre el género femenino bajo una figura de autoridad (pp. 306-310). Desde esta perspectiva, la mujer es percibida como un elemento de guerra a través de su cuerpo, catalogada como un premio o un arma por medio del cual se vulnera, suprime, minimiza o humilla al actor contrario. Así mismo, resalta que la militarización de la femineidad a través del reclutamiento de mujeres jóvenes $\mathrm{y}$ niñas se centra en aspectos socioculturales 
Cúcuta-Colombia

Vol. 1

No. 1

Jul - Dic 2016

ISSN: 2590-9215

(En línea)

PP: $73-80$ y económicos derivados de la pobreza, el patriarcado y la subordinación, hechos a través de los cuales la violencia que hace parte de la cotidianidad establece los grupos ilegales como una opción de vida.

En términos generales, en Colombia la invisibilización del género femenino, la falta de reconocimiento del mismo como seres humanos en igualdad de condiciones son hechos que contribuyen a la discriminación e incrementan la vulnerabilidad de las mujeres ante la violencia, y como respuesta a esto con el paso de los años la mujer ha estado expuesta a actos de violencia estructural, directa y cultural, amenazando su integridad y desarrollo (Fisco, 2005, pp. 125-127). Así mismo, la mujer en Colombia ha sido víctima de la violencia política, al ser desplazada, al ser las encargadas de velar por la supervivencia de su familia bajo circunstancias como el hecho de ser viudas, jefes de hogar o al tener familiares presos políticos o desaparecidos, pero también bajo el cumplimiento de papeles activo dentro de los grupos armados al margen de la ley, transfiriendo los roles domésticos a las zonas de conflicto en los que la mujer suministra los elementos necesarios para la supervivencia, convirtiéndose en enfermera, vigilante, informante y espía (Alape, 1985, pp 189) logrando establecer un gran impacto en la sociedad colombiana en la que aún se discuten los mecanismos de acceso a la justicia que reivindiquen el género femenino.

De esta manera, dentro del territorio se han gestado numerosos escenarios de dolor que promueven el desarraigo y hablan de las experiencias de crueldad y falta de protección al que se han visto expuesto el género femenino, dejando al descubierto una verdad innegable que centra a la mujer como víctima del conflicto armado, mediante un sistema de prácticas $y$ representaciones en las que la mujer se presenta como el centro de dominio y control bajo pautas ideológicas, corporales, culturales y psicológicas dentro marcos de retención, violación, prostitución y explotación sexual que se apropia de la condición de seguridad, arraigo, sentido de pertenencia y territorialidad dentro del territorio nacional (Andrade Salazar, 2010, pp. 15-16), por medio de actos violentos o de barbarie, la perdida de propiedades, las diversas situaciones de crisis emocional derivadas de amenazas, miedos, odios, inseguridades, desconfianza y dolor ante la incertidumbre y la complejidad que el conflicto armado impone, sumado a factores como la desescolarización, el desempleo y las diversas limitaciones a los bienes y servicios necesarios para una vida digna (Cifuentes, 2009, pp. 91).

Según los estudios realizados por el Centro Nacional de Memoria Historia (2011) el conflicto armado interno colombiano ha tenido efectos y consecuencias dentro de los proyectos de vida de las mujeres que han sido vulneradas, frustrando, menoscabando o postergando su realización personal, truncando sus expectativas en cuanto a la realización de sueños, teniendo en cuenta que además estos sentimientos, frustraciones y daños colaterales recaen específicamente sobre sus hijos, compañeros sentimentales, padres y demás familiares, quienes de una $\mathrm{u}$ otra forma se han sido expuestos o relacionados con ejemplos de situaciones traumáticas que tienden a desestabilizar la sensación de control, produciendo en ellos profundos y considerables cambios fisiológicos, cognitivos y de memoria.

\section{Conclusiones}

Dentro del conflicto armado interno colombiano la mujer ha desempeñado un importante papel que se enmarca en la victimización de su género debido a que durante más de cincuenta años ha sido blanco directo de vulneraciones y transgresiones con respecto a sus derechos y libertades fundamentales, estableciendo una ruptura 
en el núcleo tradicional familiar que se ha visto alterado como respuesta a la muerte, los actos violentos y la barbarie a los que ha sido sometida la población civil. Por tal razón, es de vital importancia que dentro de las políticas públicas previstas dentro del marco de los diálogos de paz que se fundamentan dentro del modelo de justicia transicional se promueva la participación de la sociedad civil, con el objetivo de establecer medidas de reparación integral.

Bajo este orden de ideas, es de vital importancia que el conflicto armado colombiano sea interpretado y regulado a partir de un enfoque diferencial con respecto a la población vulnerable, haciendo un énfasis especial en el colectivo de la mujer, señalando así mismo la necesidad de establecer investigaciones y políticas públicas eficaces, exhaustivas e imparciales que contribuyan a la reparación integral de las víctimas, entendiendo que la permanencia de la ciudad del post acuerdo se debe fundamentar mediante la recuperación de la función social, como el medio propicio para contar las historias, los hechos y las narraciones que conforman el imaginario colectivo, por medio de símbolos reparadores que propicien el reconocimiento de la dignidad de las víctimas, la preservación de la memoria histórica y la no repetición de los hechos victimizantes, favoreciendo la reconstrucción de la sociedad y la historia.

\section{Referencias}

Abc Colombia, Sisma Mujer. (2013). Colombia: mujeres, violencia sexual en el conflicto y el proceso de paz. Abc Colombia, Sisma Mujer. Londres: Abc Colombia.

Andrade Salazar, J. (2010). Mujeres, niños y niñas, víctimas mayoritarias del desplazamiento forzado. Orbis. Revista Científica Ciencias Humanas, 6(16), 28-53.

Auto 009 de 2015 (Corte Constitucional 2015).

Auto 092 de 2008 (Corte Constitucional 2008).

Cadavid Rico, M. R. (2014). Mujer: Blanco del conflicto armado en Colombia. Analecta Polit, 4(7), 301-318.

Centro Nacional de Memoria Histórica. (2011). De Cartagena a Tumaco. Un viaje a las memorias. Bogotá: Departamento para la prosperidad Social.

Centro Nacional de Memoria Histórica. (2011). Mujeres y guerra. victimas y resistentes en el caribe colombiano. Taurus.

Centro Nacional de Memoria Historica. (2011). Mujeres que hacen historia: las luchas por la reinterpretación de la violencia y la discriminación de género. La memoria histórica desde la perspectiva de género: conceptos y herramientas. CNMH, Bogota.

Cifuentes, M. (2009). Familia y conflicto armado. Revista de trabajo social(11), 87-106.

Comisión Interamericana de Derechos Humanos. (1999). Tercer informe sobre la situación de Derechos Humanos en Colombia. CIDH.

Corte Interamericana de Derechos Humanos. (2006). Las mujeres frente a la violenciayladiscriminación derivadas del conflicto armado colombiano. Secretaria General Organización de los Estados Americanos. Washintong: CIDH.

(1)

$-$

-


Cúcuta-Colombia

Vol. 1

No. 1

Jul - Dic 2016

ISSN: $2590-9215$ (En línea) PP: $73-80$ conflicto armado colombiano. Papel Politico(17), 119-159.

Grupo de Trabajo Mujer y género, por la verdad, la justicia, la reparación y la reconciliación. (2008) Recomendaciones para garantizar los derechos a la verdad, la justicia y la reparación de las mujeres víctimas del conflicto armado en Colombia, Bogotá.

Meertens, D. (1995). Mujer y violencia en los conflictos rurales. Analisis Politico(24), 1-16.

Ministerio del Interior Republica de Colombia. (2012). Ley de victimas y restitución de tierras y decretos reglamentarios. Bogota: Ministerio del Interior.

Ruta Pacifica de las mujeres. (2013). La verdad de las mujeres victimas del conflicto armado. Ruta Pacifica de las mujeres, Bogota.

Unicef; Defensoria del Pueblo(2002). La niñez en el conflicto armado colombiano. Boletin la niñez y sus derechos.

Unidad para la atención y reparación integral a las victimas. (15 de febrero de 2016). Registro Unico de Victimas. Obtenido de http://rni.unidadvictimas. gov.co/?q=node/107 